\title{
Opportunities and challenges associated with health services research of complementary medicine in France: Response to Braillon
}

Steel, Amie ${ }^{1}$

Palmgren, Per $^{2}$

Schloss, Janet ${ }^{1,3}$

Diezel, Helene ${ }^{3}$

Filbet, Marilene ${ }^{4}$

${ }^{1}$ Australian Research Centre in Complementary and Integrative Medicine, Faculty of Health, University of Technology Sydney, Ultimo, NSW, Australia

${ }^{2}$ Department of Learning, Informatics, Management and Ethics, Karolinska Institutet, Stockholm, Sweden

${ }^{3}$ Office of Research, Endeavour College of Natural Health, Brisbane, QLD, Australia

${ }^{4}$ Centre de soins palliatifs, Centre hospitalier Lyon sud, Lyon sud, France

\section{Corresponding author}

Dr Amie Steel

Amie.steel@uts.edu.au

Ph: +61 418786186

Faculty of Health

University of Technology Sydney

235-253 Jones St

Ultimo, NSW Australia 
Braillon raises some points for discussion in response to our paper "The use of complementary medicine in palliative care in France: an observational cross-sectional study" [1]. Firstly, we concur that concepts and phenomena in science need to be demarcated, defined and constantly scrutinized. We also agree that the term 'complementary medicine' (CM) is fraught at best, with its use primarily limited to be a vehicle of convenience for academics and policymakers to discuss any healthcare that is not included in mainstream health systems within any given locality [2]. As a term, it certainly has limited, if any, value in the context of understanding and providing patient-centred health services. $\mathrm{CM}$, as it is used in peer-reviewed literature and health policy, refers to such a broad selection of treatments, practices and therapies that any generalized statements about $\mathrm{CM}$ are difficult, if not impossible [3]. Equally, the subjective classification of CM is often undertaken through the sociocultural and personal biases of those applying the classification, whether they be $\mathrm{CM}$ practitioners, mainstream health professionals, independent researchers or stalwart skeptics. In this instance, we have applied a 'theoretical' definition of CM [4] - treatments and practices not included within national medical curriculum - in response to the identified gap in French health services research and policy addressing treatments that are not considered part of mainstream healthcare.

Braillon rightly emphasizes the importance of evidence for both benefit and safety of healthcare accessed by the public. We hold the view that it is the responsibility of the research community to serve the wider population by undertaking rigorous research to address any gaps in such evidence and, in doing so, inform future evidence-based decision-making. We also believe that research is about transparency, the creation of new knowledge and the use of existing knowledge in a new way to generate new concepts, methodologies and further understanding. Our research offers readers, such as researchers and policymakers, an opportunity to prioritize resources (both human and fiscal) based on evidence of use rather than personal bias or conjecture; and in our reckoning the most commonly used treatments and practices should be among those prioritized for future research. We concede that the practice of medicine has many connotations and one's perspective of its concepts is influenced by the beholder's paradigmatic stance. As co-authors, we take a rather pragmatic stance and view the practice of medicine through the lens of the evidence-based practice model, thus involving the conscious and systematic use of several sources of knowledge for decisionmaking: the best available knowledge, the professional expertise, experience and wishes of the patient concerned, but also the patient's situation and contextual circumstance [5]. With this in mind, we acknowledge Braillon's interest in homeopathy however we would suggest that, based on the evidence presented in our study, aromatherapy (products and practice), Coupeurs de feu, osteopathy and vitamins warrant equal or greater attention for further research. Our paper presents preliminary clinical research examining some of these practices, but also acknowledges the evidence gaps. It is our hope that our research will stimulate academic and government interest in these practices and result in knowledge production that strengthens a patient's capacity to make informed healthcare decisions.

Based on the scarcity of empirical data regarding the use of $\mathrm{CM}$, especially among cancer patients in France, we employed a descriptive rationale in our study. Thus, the aim of our paper was to describe the use of $\mathrm{CM}$ by individuals receiving palliative care in Lyon, France. However, we also acknowledged in our paper that this study is restricted to Lyon; a location with its own historical and sociocultural factors that may influence health service use. Given the surprisingly high prevalence of $\mathrm{CM}$ use, we have also raised the question presented by Braillon regarding the degree to which the findings from our study are reflective of health service use patterns across France. We look forward 
to future research answering such questions and, rather than speculating based on local data, have called for such research to be conducted. We maintain that our work is a first step to elucidate this current gap of knowledge and anticipate the new knowledge that will evolve regarding CM use in palliative care settings.

\section{Conflict of Interest}

The authors have no conflict of interest to declare

\section{References}

1. Filbet, M., et al., The use of complementary medicine in palliative care in France: an observational cross-sectional study. Supportive Care in Cancer, 2020: p. 1-8.

2. Holmberg, C., B. Brinkhaus, and C. Witt, Experts' opinions on terminology for complementary and integrative medicine-a qualitative study with leading experts. BMC complementary and alternative medicine, 2012. 12(1): p. 218.

3. Murphy, L.S., et al., Searching biomedical databases on complementary medicine: the use of controlled vocabulary among authors, indexers and investigators. BMC Complementary and Alternative Medicine, 2003. 3(1): p. 3.

4. Wieland, L.S., E. Manheimer, and B.M. Berman, Development and classification of an operational definition of complementary and alternative medicine for the Cochrane collaboration. Alternative therapies in health and medicine, 2011. 17(2): p. 50.

5. Sackett, D.L., et al., Evidence based medicine: what it is and what it isn't. 1996, British Medical Journal Publishing Group. 